\title{
The Italian National Beekeeping Registry (BDNA) as a Tool to Identify Areas Suitable for Controlled Mating of Honey Bees in Italy
}

\author{
Franco Mutinelli ${ }^{1,2, *}$, Matteo Mazzucato ${ }^{1}$, Marco Barbujani ${ }^{1}$, Emanuele Carpana ${ }^{2,3}$, Vincenzo Di Salvo ${ }^{2,4}$, \\ Tiziano Gardi ${ }^{2,5}$, Daniele Greco ${ }^{2,6,+}$, Luca Bonizzoni ${ }^{2,7,+}$, Massimo Benvenuti ${ }^{2,8}$, Claudia Casarotto ${ }^{1}$, \\ Laura Bortolotti ${ }^{1}$ and Cecilia Costa ${ }^{2,3}$ \\ Citation: Mutinelli, F.; \\ Mazzucato, M.; Barbujani, M.; \\ Carpana, E.; Di Salvo, V.; Gardi, T.; \\ Greco, D.; Bonizzoni, L.; \\ Benvenuti, M.; Casarotto, C.; et al. \\ 1 NRL for Honey Bee Health, Istituto Zooprofilattico Sperimentale Delle Venezie, 35020 Legnaro (PD), Italy; \\ mmazzucato@izsvenezie.it (M.M.); marco.barbujani@unipd.it (M.B.); ccasarotto@izsvenezie.it (C.C.); \\ lbortolotti@izsvenezie.it (L.B.) \\ 2 CTC Dell'Albo Nazionale Degli Allevatori di Api Italiane (National Registry of Italian Bee Breeders), \\ 40128 Bologna, Italy; emanuele.carpana@crea.gov.it (E.C.); vdisalvo@regione.emilia-romagna.it (V.D.S.); \\ tiziano.gardi@unipg.it (T.G.); info@apicolturailgiglio.it (D.G.); info@lucabonizzoni.it (L.B.); \\ m.benvenuti@politicheagricole.it (M.B.); cecilia.costa@crea.gov.it (C.C.) \\ 3 Council for Agricultural Research and Economics (CREA), Research Centre for Agriculture and \\ Environment (CREA-AA), 40128 Bologna, Italy \\ 4 Direzione Generale Agricoltura, Caccia e Pesca Servizio Organizzazioni di Mercato e Sinergie di Filiera, \\ Regione Emilia Romagna, 40127 Bologna, Italy \\ 5 Dipartimento di Scienze Agrarie, Alimentari e Ambientali, Università di Perugia, 06121 Perugia, Italy \\ 6 Independent Researcher, 73100 Lecce, Italy \\ 7 Independent Researcher, 27045 Casteggio (PV), Italy \\ 8 Dipartimento Delle Politiche Europee e Internazionali e Dello Sviluppo Rurale-Direzione Generale dello \\ Sviluppo Rurale, MIPAAFT, 00187 Roma, Italy \\ * Correspondence: fmutinelli@izsvenezie.it; Tel.: +39-049-8084287 \\ + Professional beekeeper and member of CTC.
} The Italian National Beekeeping Registry (BDNA) as a Tool to Identify Areas Suitable for Controlled Mating of Honey Bees in Italy. Appl. Sci. 2021, 11, 5279. https://doi.org/10.3390/ app11115279

Academic Editor: Jerzy Wilde

Received: 1 April 2021

Accepted: 2 June 2021

Published: 7 June 2021

Publisher's Note: MDPI stays neutral with regard to jurisdictional claims in published maps and institutional affiliations.

Copyright: (c) 2021 by the authors. Licensee MDPI, Basel, Switzerland. This article is an open access article distributed under the terms and conditions of the Creative Commons Attribution (CC BY) license (https:/ / creativecommons.org/licenses/by/ $4.0 /)$.
Abstract: Honey bee mating is difficult to control as it occurs in flight, several kilometers away from the hive of origin of both queens and drones. In recent years, there has been an increase in the introduction into Italy of queen bees and swarms originating from interracial crossings (especially those known as "Buckfast"), or belonging to non-native subspecies. Consequently, there is a strong need to establish areas suitable for controlled mating. The Italian national beekeeping registry (BDNA) has been recently set up to monitor the position of apiaries and movement of hives, with the purpose of economic and sanitary protection and improvement of bee heritage and food safety. The BDNA was, thus, deemed a suitable tool to explore the availability of areas that could be used as mating stations. Specific criteria, such as not be classified as wetlands, altitude below $1500 \mathrm{~m}$ a.s.l., distance of at least $6000 \mathrm{~m}$ from an apiary, and distance of at least $1500 \mathrm{~m}$ from the national terrestrial border, were selected for defining the mating stations. Furthermore, all the remaining Italian national territory was considered suitable for settlement of mating stations, including towns, industrial settlements, and roads. Based on these criteria, the following methodological framework was applied: (1) collection of the required data (i.e., apiaries coordinates, geospatial data on soil classification, geospatial data on terrain altitude, Italian boundary geospatial data); (2) calculation for the excluded areas according with the criteria listed above; (3) calculation of the mating areas by means of the difference between the entire Italian territory and the excluded areas. The database of BDNA was used to identify them. Appropriate databases and software were used to exclude the areas of the Italian national territory that did not fulfill the established criteria. In this paper, we report the procedure applied to identify on maps the areas suitable for controlled mating of queen bees in the Italian national territory based on data currently available in the BDNA.

Keywords: national beekeeping registry (BDNA); GIS; honey bee; Italy; mating station; queen bee 


\section{Introduction}

Honey bee mating, differently from farmed animals, is difficult to control, as it occurs in flight, several kilometers away from the hives of origin of the mating bees. It has been shown, that on the basis of the orographic characteristics of the territory, virgin queens and drones move up to 5-8 $\mathrm{km}$ towards areas located at the height of $10-30 \mathrm{~m}$, defined as "drone congregation areas" (DCA), where a queen mates with about 20 drones [1-4].

In recent decades, there has been an increase in the introduction in Italy of queen bees and swarms originating from interracial crossings (especially those known as "Buckfast") or belonging to subspecies non-native to the Italian peninsula (especially Apis mellifera carnica, the autochthonous subspecies of the central-eastern Europe). The increasingly frequent reports from individual beekeepers and from the press information bodies of the beekeeping sector, are also confirmed by the Ministry of Health, which receives applications for the issue of authorization to import thousands of queens from third countries, as well as by the growing number of hybrid samples found in the analysis for the subspecies certification carried out by the Council for Agricultural Research and Economics - Research Centre for Agriculture and Environment (CREA-AA, formerly Research Unit of beekeeping and sericulture) and by the Istituto Zooprofilattico Sperimentale del Lazio e della Toscana. Consequently, initiatives are necessary for the conservation and genetic improvement of the subspecies A. m. ligustica, including the establishment of officially protected areas for the mating of queen bees.

Optimal criteria for establishment of mating stations are as follows: absence or minimal presence of managed and unmanaged honey bee colonies and airborne drones in a radius of at least $6 \mathrm{~km}$; favorable pollen and nectar resources; weather conditions with long periods of more than $20^{\circ} \mathrm{C}$ ambient temperature, and wind speed not more than $24 \mathrm{~km} / \mathrm{h}$; undulating landscape and sheltered areas for positioning of mating boxes. Furthermore, markers, such as stones, trees, bushes, or purposely installed objects help to minimize queen drifting and losses [5]. To ensure a strong drone population for mating sufficient drone colonies should be granted. A minimum of 8 to 10 strong drone colonies, or 1 drone colony per 25 queens are recommended [6]. Minimal presence of honey bee predator species is also suggested [5].

The database of the national beekeeping registry (BDNA), referred to in the decrees of the Ministry of Health of 2009, 2014 and 2017 [7-9], has the purpose of:

- $\quad$ economic-sanitary protection and improvement of the bee heritage, food safety, and pharmaco-surveillance;

- $\quad$ monitoring of the movements of the hives;

- protection and safeguard of the environment and the ecosystem.

Overall, it constitutes a tool for the improvement of knowledge of the beekeeping sector in terms of production and health. To achieve these objectives, it is essential to know who the beekeepers are, what type of activity they carry out, where the apiaries are located, how many colonies are kept and their movements. In short, the main issues are tracking and traceability. These data are recorded by the veterinary services, by beekeepers, by associations delegates, each for their own competences, in the national system of the BDNA which, in addition to responding to the institutional purposes mentioned above, could also be useful for other purposes of interest of the beekeepers. One application is a better knowledge of the distribution of apiaries on the territory for identifying areas suitable for the establishment of mating stations for queen bees.

The National Registry of Italian Bee Breeders approved by Ministerial Decree n. 1839 of 30 January 2013 [10] has the aim of protecting the Italian autochthonous subspecies by means of increasing their commercial value. In the specifications of the registry operating protocol, it is foreseen that breeders should use protected mating stations to ensure maintenance of subspecies standards and to enact breeding programs. Thus, as part of the activities proposed by the Central Technical Commission (CTC) of the same National Registry, an attempt was made to define specific criteria that an area must possess for the 
establishment of a mating station, and to use the data currently available in the BDNA to identify potentially suitable areas on the Italian territory and display them on maps.

The request derives from the need to have a minimum area in which there is a reasonable guarantee of the absence of apiaries (and consequently of unknown drones) that could interfere with the mating of the queen bees of a bee breeder or of a breeding group who carry out their activity with colonies of a specific subspecies or belonging to local populations or who are engaged in a program of genetic improvement. The absence of apiaries would, therefore, represent the ideal solution and the one to be preferred in order to guarantee the objectives of the conservation and genetic improvement program. Despite the provisions of the Breeders' National Registry, that the mating station must be at a minimum distance of $3 \mathrm{~km}$ from other apiaries whose genetic characteristics are not known, in agreement with the general recommendations [5] that indicate a distance of $6 \mathrm{~km}$ from other apiaries, the Committee of the Registry decided to use this $6 \mathrm{~km}$ radius, as minimum distance for assessing areas suitable for setting up mating stations in the present investigation. In this regard, we also recall the recently approved regional law of the Italian region Emilia Romagna which, in article 7 "Protection of the Apis mellifera subspecies ligustica", provides for the possibility that suitable buffer areas can be established around collective mating stations for queen bees [11]. In addition, the possibility of establishing protected buffer areas for the breeding of queen bees for selective or commercial purposes is also afforded by the beekeeping legislation of various Italian regions.

The tool used to identify areas characterized by the absence of apiaries is the Geographic Information System (GIS). GIS is a framework for gathering, managing, and analyzing geographical data. GIS operates on many levels. On the most basic level, GIS technology is used as computer cartography, that is for straightforward map making. The real power of GIS, however, is through using spatial and statistical methods to analyze attribute and geographic information. For example, using GIS, a single map could include sites that produce pollution, such as factories, and sites that are sensitive to pollution, such as wetlands and rivers. Such a map would help people determine where water supplies are most at risk. GIS can be used alone or in combination with other technologies including remote sensing to perform the required analysis. Remote sensing consists of information acquired from satellite or aerial images. These images are incorporated directly into the GIS application, or they can be elaborated according to a framework to obtain maps and spatial data. A typical example of satellite image framework elaboration is the CORINE Land Cover (CLC, https:/ / land.copernicus.eu/global/, accessed on 18 May 2021). The objective of the CLC project is the provision of a unique and comparable dataset of land cover for Europe. In the GIS spatial analysis, the CLC data are used for characterizing and describing the land use and land cover information of the territory [12,13].

There are also studies related to honey bees and beekeeping, where GIS can be utilized to select suitable locations for apiaries, to map bee plants, to study bee behavior, diseases and pests, and to predict the effects of climate change on honey bees beside other benefits for beekeeping. One of the most common uses of GIS in honey bees and beekeeping applications is to identify the best locations to establish new apiaries within a given geographical location. Geographical datasets used to realize this type of studies include, the apiaries location, land use, and altitude [14-17].

In this preliminary study, we have attempted to integrate the BDNA and the GIS methodology as useful tools for selecting areas for establishing mating stations at a country level.

\section{Materials and Methods}

For the realization of this preliminary study, the areas suitable for the establishment of the mating stations of queen bees (hereafter mating areas) were determined according to the criteria proposed in the CTC 2016-2018 of the National Registry of Italian Bee Breeders, with the exception of the minimum distance from other apiaries which followed the indications contained in Büchler et al. [5]: 
- distance of at least $6000 \mathrm{~m}$ from an apiary;

- not be classified as wetlands;

- $\quad$ altitude below $1500 \mathrm{~m}$ above sea level (a.s.l.);

- distance of at least $1500 \mathrm{~m}$ from the national terrestrial border.

All the remaining Italian national territory was considered suitable for settlement, including towns, industrial settlements, and roads.

Following these criteria, the methodological framework used to identify the mating areas in the Italian national territory is composed of the following steps:

(1) collection of the required data (i.e., apiaries coordinates, geospatial data on soil classification, geospatial data on terrain altitude, Italian boundary geospatial data);

(2) calculation for the excluded areas (i.e., areas within the distance of $6000 \mathrm{~m}$ from every apiaries, areas classified as wetland, areas which altitude is above $1500 \mathrm{~m}$, areas within the distance of $1500 \mathrm{~m}$ from the Italian boundary);

(3) calculation of the mating areas by means of the difference between the entire Italian territory and the excluded areas.

The whole procedure is depicted in Figure 1.

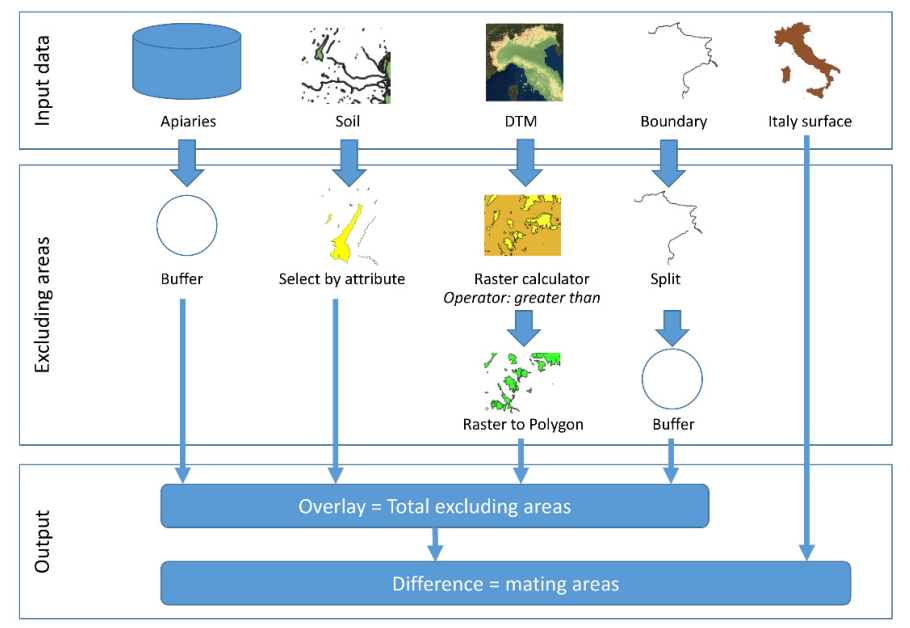

Figure 1. Flow chart representing the mapping procedure for calculating the mating areas.

\subsection{Collection of the Required Data}

The information on the geographic coordinates of the apiaries registered on a national level was replicated at the National Reference Center for Beekeeping at the Istituto Zooprofilattico Sperimentale delle Venezie (IZSVe) using the download tools (a dedicated IT procedure based on synchronous web service protocols) made available by the BDNA. The BDNA is based on a software used by the Italian local health units personnel to input apiary data. For each apiary, the BDNA software stores the coordinates of its location together with the number of beehives and swarms/nuclei, as well as information, such as the beekeeper's name and address. According to the Italian legislation [8], between November and December of each year, the Veterinary Services of the local health units perform a census of the apiaries present in the Italian territory. The census is aimed at updating the information about new beekeepers, beekeepers that ceased their activities, the location of apiaries, the number of beehives and swarms/nuclei present in the apiaries. Moreover, every year, the local health units have to select $1 \%$ of apiaries located in their territory to inspect and check the information stored in the BDNA. The BDNA software is built for compulsory input of the geographical coordinate values of an apiary location every time a new beekeeper is registered or the location of apiaries is changed. To insert or update the geographical coordinates in the BDNA software, two methods are offered, the direct and the indirect method. The direct method is based on the use of GPS: the beekeepers by means of a GPS device (even a smartphone, which nowadays offer applications with 
the GPS functionalities) record the coordinates and inform the local health unit about the apiary location, providing the information that is imputed in the software by the operator. The indirect method is based on the use of digital cartography. The BDNA software allows the operator to open a new frame in the computer screen where a digital map offered by Google appears together with some functionalities, which allows the geolocation of the point where the apiaries are located. The result of the geolocation operation is the calculation of the apiaries' geographical coordinates. The BDNA software uses as geographical coordinate system the WGS84 (description about the WGS84 coordinate system can be found in the EPSG web site: https:/ / epsg.org/home.html (accessed on 18 May 2021) and the coordinates are expressed in decimal degree (i.e., "GG, dddddd" where "G" means degree, and " $\mathrm{d}$ " decimal degree).

For the geospatial information about wetlands located in the Italian territory, the Soil Cover classification of the CORINE Land Cover (CLC) inventory was used (information about the CORINE project can be found in the Copernicus project web site: https:/ /land. copernicus.eu/pan-european/corine-land-cover (accessed on 10 May 2021). The 2018 version of the CLC was used (v.2020_20u1 https://land.copernicus.eu/pan-european/ corine-land-cover/clc2018, accessed on 18 May 2021). Given the CLC data, all areas belonging to the first level CLC class 4 (humid environment) or 5 (water environment) were derived.

For the information about areas higher than $1500 \mathrm{~m}$ a.s.l. the digital terrain model (DTM) provided by the Italian geoportal (http:/ / www.pcn.minambiente.it/mattm/schedametadati, accessed on 31 May 2021) was used. A DTM is a topographic model of the Earth that can be manipulated by GIS software. The DTM geospatial data files are organized as a grid where the cells contain the value of the altitude. An example of the DTM used for this study is presented in Figure 2. The DTM used in this study covers the whole National territory and it is provided in matrix (raster) format. The model is obtained by means of different methodologies (i.e., photo-grammetric restitution of numerical data, generalization of numerical cartography, semi-automatically by stereo-restitution) from Italian Military Geographic Institute's (IMGI) orographic data of 25 and 25DB series maps. IMGI is the Army's geographic supporting office and also the National Cartographic Authority; the cartography produced by IMGI is considered the official state cartography. The Series 25 and 25DB maps, named the "Topographic Map of Italy" at scale 1:25,000, consists of a series of maps carried out by digital stereo-restitution or from regional technical numerical cartography derivation. The resulting DTM product is a matrix, whose elements (pixel) indicate elevation with a spatial resolution of $20 \mathrm{~m}$ in the planar dimension and $5 \mathrm{~m}$ for the vertical dimension at scale of 1:25,000 with a degree of accuracy of 3-4 tenths millimeter graph. The altitude value for each pixel is the mean value recorded in the pixel area. The pixel value is referred to the barycenter of the cell. The DTM creation started during the 80s and was completed on 12 February 2001 (http:/ / www.pcn.minambiente.it/ mattm/visualizzazione-metadati/?keyword=dem, accessed on 31 May 2021). From the DTM geospatial data it is possible to select the cells with an altitude value greater than $1500 \mathrm{~m}$.

For the information about the areas located at a distance of less than $1500 \mathrm{~m}$ from the national terrestrial border, a buffer with a radius of $1500 \mathrm{~m}$ from the Italian boundary provided by Italian geoportal was used (data source for Italian boundary: National Geoportalhttp:/ / www.pcn.minambiente.it/mattm/visualizzazione-metadati/?keyword=confini, accessed on 10 May 2021). In particular the terrestrial borderline was obtained by a cutting operation of the Italian borderline and taking into account only the borderline that ranges from Liguria to Friuli Venezia Giulia (Alpine Arch) regions. 




Figure 2. These maps are print screens obtained from the Italian geoportal (http://www.pcn. minambiente.it/viewer/index.php?services=dtm_20m, accessed on 31 May 2021). The left image is the representation of the territory derived from satellite data, where it is visually possible to recognize the territory's orography. The right image is the DTM image of the same portion of territory. The image is in reality geospatial data composed of pixels whose values represent the altitude. A chromatic scale, which range from green to brown, is used to represent the altitude variation.

\subsection{Calculation for the Excluded Areas}

To exclude the areas that are within the distance of $6000 \mathrm{~m}$ from any apiary, the buffer tool was applied. "Buffer" is one of the most important geoprocessing operations and frequently used in GIS projects [14]. A buffer increases a feature's area by a given radius, exactly following its original geometry (point, line, or polygon). For the calculation of the areas to exclude, BDNA data were used, and in particular all the apiaries as of December 2019. A total of 143,738 apiaries were extracted and used to calculate the buffer areas (Figure 3a). The set of all calculated buffers (Figure 3b) was then used to exclude these portions of territory from the national surface (due to the presence of apiaries within $6000 \mathrm{~m}$ radius).



Figure 3. (a) Around each apiary present in the BDNA a buffer area was created with a radius of $6 \mathrm{~km}$ which corresponds to a surface of $113 \mathrm{~km}^{2}$. The black dot indicates an apiary in the BDNA, the red circle the area resulting from applying a $6 \mathrm{~km}$ radius, the pink area represents the excluded area, and the white area the potentially suitable area. (b) The resulting excluded area due to the presence of apiaries is spatially represented by a series of buffers. (c) The area not included in the buffers, and not excluded by other criteria (in red), was considered as "suitable area for the establishment of mating stations".

To exclude the wetland areas an attribute selection function was used [14]. The CLC attribute value equal to 4 (humid environment) or 5 (water environment) were used as filter option and the resulting geospatial data were used to exclude these portions of territory.

To exclude the areas above $1500 \mathrm{~m}$ of altitude the operation performed mixed raster map algebra instruments with the vector functions [14]. The first step was to apply a filter to the pixel values greater than $1500 \mathrm{~m}$. The next step was to convert the selected pixel into a vector geospatial data (raster-to-vector operation). The resulting geospatial data were used to exclude the portions of territory above $1500 \mathrm{~m}$. 
To exclude the areas within the distance of $1500 \mathrm{~m}$ from the Italian boundary, the already above mentioned buffer operation was used.

All the resulting excluded areas were than merged together by a union operation in order to obtain the total excluded areas. To derive the portions of potentially suitable areas for the establishment of mating stations, a difference operation between the total Italian territory and the total excluded areas was made. As shown in Figure 3c, the total area is made up by the sum of portions of geographically distinct suitable areas.

All operations were carried out using the ESRI ${ }^{\mathrm{TM}}$ ArcMap 10.5.1 GIS software (http: / / desktop.arcgis.com/en/arcmap/, accessed on 10 May 2021). ArcGIS is a GIS for working with maps and geographic information maintained by the Environmental Systems Research Institute (Esri). It is used for creating and using maps, compiling geographic data, analyzing mapped information, sharing and discovering geographic information, using maps and geographic information in a range of applications, and managing geographic information in a database.

\section{Results}

A total number of 143,738 apiaries was extracted from the BDNA; the total excluded areas due to the presence of apiaries is equal to $298,856 \mathrm{~km}^{2}$. A total of 1090 wetlands were identified resulting in a total excluded area due to wetlands of $3983 \mathrm{~km}^{2}$. The amount of areas located above the $1500 \mathrm{~m}$ is $24,549 \mathrm{~km}^{2}$. Finally, the excluded areas due to the proximity of $1500 \mathrm{~m}$ from the Italian boundary is $2567 \mathrm{~km}^{2}$. The total excluded area derived from the geographical union of the single excluded areas is $300,088 \mathrm{~km}^{2}$.

A total of 136 areas were identified (6 small areas with a surface value less than 0.09 hectares have been excluded from the analysis) as suitable areas for establishment of mating stations, summing up to a total of $1977.59 \mathrm{~km}^{2}$, corresponding to approximately $0.65 \%$ of the Italian national surface. The surface of the identified areas ranges from 0.0014 $\mathrm{km}^{2}$ up to $696.16 \mathrm{~km}^{2}$. In Figure 4, the density distribution of the mating areas surface is presented. The distribution shows a strong asymmetry due to the presence of many small values. In particular, the distribution showed a median value of $1.3 \mathrm{~km}^{2}$ and the last 25th percentile has a value of $4 \mathrm{~km}^{2}$.



Figure 4. Density distribution of the mating areas surfaces.

The geographical distribution of mating area is presented in Figure 5a-d. The majority of mating areas are located in southern Italy and in the two main islands, namely Sicily and Sardinia. The territory with the majority of mating areas is located in Puglia region (26 mating areas) with an available surface of $1139 \mathrm{~km}^{2}$. In Puglia the largest mating area in a single body, with an extension of $696 \mathrm{~km}^{2}$, is also located. The other two regions with high number of mating areas are Calabria (14 mating areas equal to $158 \mathrm{~km}^{2}$ ) and Sicily (13 mating areas equal to $328 \mathrm{~km}^{2}$ ). 


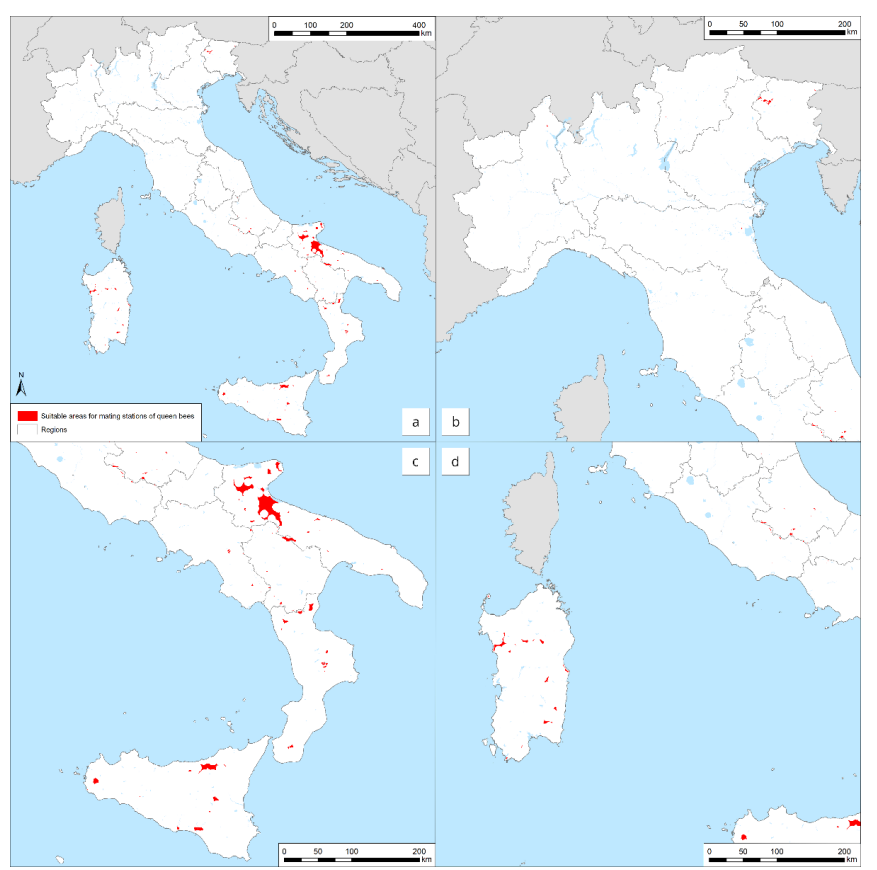

Figure 5. (a) Comprehensive distribution and location of the possible suitable areas for establishment of mating stations in the Italian territory; (b) detail of central-north Italy; (c) detail of central-south Italy; and (d) detail of Sardinia region. Red areas are those suitable for potentially establishing mating stations. The Italian territory is shown with borders among regions.

\section{Discussion}

In the preliminary study presented here, conducted as part of the activities proposed by the CTC of the National Registry of Italian Bee Breeders-2016-2018 mandate, an attempt was made to identify areas in Italy which could be suited for the establishment of mating stations for queen bees, based on the data currently available in the BDNA and using criteria for isolation agreed upon by breeders and beekeepers representatives and scientific experts [5]. The obtained results show that the overwhelming majority of the 136 identified areas have a small surface value.

Looking at the distribution of suitable areas across the country, we observed that in the central-northern Italy, the presence of the areas is extremely low and limited to hilly and mountainous areas. In central-southern Italy, the areas appear to be concentrated along the Apennine ridge, as well as covering large areas of territory in Puglia and in the two major islands. In these regions, the areas with the largest extension in a single body are also found. Furthermore, the region with the largest proportion of land suitable for establishing mating stations, equal to $57.6 \%$ of the entire suitable mating area, is Puglia.

Given that the distance for isolation of a mating station used in this study is internationally recognized [5], we found that the availability of suitable areas in Italy is really very low. Notwithstanding, an optimistic outlook could be the fact that apiaries belonging to bee breeders were also considered and that some apiaries may still be registered as such but not actually have contained any hives. In fact, until 2019 it was not compulsory to "close" an apiary even if all beehives had been removed.

Abou-Shaara [15] recently reviewed the application of GIS methodology for beekeeping development and underlined that it has been used in relatively few studies related to honey bees and beekeeping. He reviewed previous investigations on GIS and honey bees, beekeeping and bee products considering potential trends for GIS application. Among them the possible role of GIS for establishment of honey bee mating stations was also considered. Our preliminary study allowed to visualize the extent, dimension, and distribution of areas in which mating stations could be established for controlled honey bee breeding in Italy, based on the eligibility criteria agreed by the CTC of the National Registry 
of Italian Bee Breeders and the relevant literature, as well as on the BDNA data. Further investigation in loco is necessary in order to verify the characteristics and accessibility of these areas for a successful use toward this purpose. Given the present availability of mating stations in the Italian territory according to the above mentioned criteria, it clearly appears that the chances for the use of this tool for the conservation and genetic improvement of the subspecies A. m. ligustica are extremely scarce. Nevertheless, bee breeders could consider compensating the described conditions by involving neighboring beekeepers and by utilizing instrumental insemination of queen bees in cases where absolute certainty of drone origin is necessary for the breeding program [18].

Although there are limitations, this study shows that the BDNA in association with GIS methodology could represent a useful tool in the future for selecting areas for establishing mating stations at country level. Furthermore, the study highlights the need for a steady update of the data of the BDNA and also for an improvement in their completeness and data quality.

Author Contributions: Conceptualization, F.M. and C.C. (Cecilia Costa); methodology, M.M., M.B. (Marco Barbujani), C.C. (Claudia Casarotto); data curation, L.B. (Laura Bortolotti), F.M.; supervision, E.C., V.D.S., T.G., M.B. (Massimo Benvenuti); visualization, D.G., L.B. (Luca Bonizzoni); writingoriginal draft preparation, F.M.; writing-review and editing, C.C. (Cecilia Costa), F.M., M.M. All authors have read and agreed to the published version of the manuscript.

Funding: This research received no external funding.

Institutional Review Board Statement: Not applicable.

Informed Consent Statement: Not applicable.

Data Availability Statement: Data used in this study were retrieved from the Italian national beekeeping registry (BDNA) and cannot be made available as they contain sensitive personal data.

Conflicts of Interest: The authors declare no conflict of interest.

\section{References}

1. Peer, D.F. Further studies on the mating range of the honey bee, Apis mellifera L. Can. Entomol. 1957, 89, 108-110. [CrossRef]

2. Zmarlicki, C.; Morse, R.A. Drone congregation areas. J. Apic. Res. 1963, 2, 64-66. [CrossRef]

3. Crane, E. Bees and Beekeeping — Science, Practice and World Resources; Heinemann Newnes: Oxford, UK, 1990; pp. 77-79.

4. Königer, N.; Königer, G. Mating flight duration of Apis mellifera queens: As short as possible, as long as necessary. Apidologie 2007, 38, 606-611. [CrossRef]

5. Büchler, R.; Andonov, S.; Bienefeld, K.; Costa, C.; Hatjina, F.; Kezic, N.; Kryger, P.; Spivak, M.; Uzunov, A.; Wilde, J. Standard methods for rearing and selection of Apis mellifera queens. J. Apic. Res. 2013, 52. [CrossRef]

6. Tiesler, F.K.; Englert, E. Aufzucht, Paarung und Verwertung von Königinnen; Ehrenwirth Verlag: München, Germany, 1989.

7. Decreto 4 dicembre 2009. Disposizioni per L'anagrafe Apistica Nazionale. [Decree 4 December 2009. Provisions for the National Beekeeping Registry]. GURI, n. 93. 22 April 2010. Available online: https://www.gazzettaufficiale.it/eli/gu/2010/04/22/93/ $\mathrm{sg} / \mathrm{pdf}$ (accessed on 8 January 2021).

8. Ministero Della Salute. Approvazione del Manuale Operativo per la Gestione Dell'anagrafe Apistica Nazionale, in Attuazione Dell'articolo 5 del Decreto 4 Dicembre 2009, Recante: "Disposizioni per L'Anagrafe Apistica Nazionale". [D. M. 11 August 2014. Approval of the Operating Manual for the Management of the National Beekeeping Registry, in Implementation of Article 5 of the Decree of 4 December 2009]. GURI, n. 291. 16 December 2014. Available online: https://www.gazzettaufficiale.it/eli/id/20 14/12/16/14A09510/sg (accessed on 8 January 2021).

9. Decreto Interdirettoriale 22 November 2017 Della Direzione Generale Della Sanità Animale e dei Farmaci Veterinari del Ministero Della Salute e Della Direzione Generale Dello Sviluppo Rurale del Ministero Delle Politiche Agricole, Alimentari e Forestali [Interdirectoral Decree 22 November 2017 of the Directorate General for Animal Health and Veterinary Medicines of the Ministry of Health and the Directorate General of Rural Development of the Ministry of Agricultural, Food and Forestry Policies] (002711527/11/2017-DGSAF-MDS-P). 2017. Available online: https://www.trovanorme.salute.gov.it/norme/renderNormsanPdf?anno= $2017 \&$ codLeg $=62419 \&$ parte $=1 \% 20 \&$ serie $=$ null $($ accessed on 8 January 2021).

10. Decreto del Ministero Delle Politiche Agricole Alimentari e Forestali n. 1839 del 30 Gennaio 2013 che Approva il Regolamento dell'Albo Nazionale Degli Allevatori Api Italiane e il Relativo Disciplinare Tecnico. [Decree of the Ministry of Agricultural, Food and Forestry Policies no. 1839 of 30 January 2013 approving the Regulation of the National Registry of Italian Bee Breeders and related technical standards]. 2013. Available online: https://www.crea.gov.it/documents/71515/0/Api_it_disciplinare.pdf/a906 3372-a0d0-3b84-ee42-9efa405695a3?t=1579185596323 (accessed on 8 January 2021). 
11. Legge Regionale 4 Marzo 2019, n. 2. Norme per lo sviluppo, l'esercizio e la Tutela dell'apicoltura in Emilia-Romagna. Abrogazione Della Legge Regionale 25 Agosto 1988, n. 35 e dei Regolamenti Regionali 15 Novembre 1991, n. 29 e 5 Aprile 1995, n. 18. [Regional Law 4 March 2019, n. 2. Rules for the Development, Functioning and Protection of Apiculture in Emilia-Romagna. Repeal of the Regional law 25 August 1988, No. 35 and of the Regional Regulations 15 November 1991, No. 29 and 5 April 1995, No. 18]. GURI, 3a Serie Speciale-Regioni n. 22. 1 June 2019. Available online: https:/ / www.gazzettaufficiale.it/eli/id/2019/06/01/19R00148/S3\#: \{\}:text=La\%20Regione\%20Emilia\%2DRomagna\%20 riconosce,sviluppo\%20dell \T1 \textquoterightagricoltura\%20in\%20generale (accessed on 8 January 2021).

12. Wilson, J.P. Local, national, and global applications of GIS in agriculture. In Geographical Information Systems: Principles, Techniques, Management, and Applications, 2nd ed.; Longley, P.A., Goodchild, M.F., Maguire, D.J., Rhind, D.W., Eds.; John Wiley and Sons: New York, NY, USA, 1999; pp. 981-998.

13. EFSA Panel on Animal Health and Welfare (AHAW). Assessing the health status of managed honey bee colonies (HEALTHY-B): A toolbox to facilitate harmonised data collection. EFSA J. 2016, 14, 4578. [CrossRef]

14. Rogers, S.R.; Staub, B. Standard use of Geographic Information System (GIS) techniques in honey bee research. J. Apic. Res. 2013, 52. [CrossRef]

15. Abou-Shaara, H.F. Geographical Information System for beekeeping development. J. Apic. Sci. 2019, 63, 5-16. [CrossRef]

16. Camargo, S.C.; Garcia, R.C.; Feiden, A.; De Vasconcelos, E.S.; Pires, B.C.; Hartleben, A.M.; De Moraes, F.J.; De Oliveira, L.; Giasson, J.; Mittanck, E.S.; et al. Implementation of a geographic information system (GIS) for the planning of beekeeping in the west region of Paraná. An. Acad. Bras. Ciênc. 2014, 86, 955-971. [CrossRef] [PubMed]

17. Zoccali, P.; Malacrinò, A.; Campolo, O.; Laudani, F.; Algeri, G.M.; Giunti, G.; Strano, C.P.; Benelli, G.; Palmeri, V. A novel GIS-based approach to assess beekeeping suitability of Mediterranean lands. Saudi J. Biol. Sci. 2017, 24, 1045-1050. [CrossRef] [PubMed]

18. Cobey, S.W.; Tarpy, D.R.; Woyke, J. Standard methods for instrumental insemination of Apis mellifera queens. J. Apic. Res. $2013,52$. [CrossRef] 